\title{
A Gramática e os Conteúdos da PercepÇão
}

Grammar AND THE CONTENTS OF PERCEPTION

\author{
DANIEL DEBARRY \\ Universidade Federal de Minas Gerais/CAPES, BRASIL \\ daniel.debarry@gmail.com
}

\begin{abstract}
This paper aims to critically discuss representationalist and anti-representationalist positions regarding perceptual experience - at the same time as it seeks to take a stand in favor of the former rather than the latter. Taking as starting point the so-called "McDowellTravis Debate", we intend to hold two possible notions of seeing as/seeing that to respond Travis's anti-representationalist argument: on the one hand, McDowell's idea that thinkables can figure as contents of perceptual experience; on the other, a phenomenological and Heideggerian proposal that takes the content of perceptual experience in terms of its meaning.

Keywords: Representationalism $\bullet$ anti-representationalism $\bullet$ McDowell $\bullet$ Travis $\bullet$ Heidegger - conceptualism
\end{abstract}

\section{Introdução}

Neste texto, pretendo defender uma posição representacionista e conceitualista com relação à experiência perceptual. Autores como McDowell (2005; 2009; 2018a) têm argumentado em favor da ideia de que a experiência perceptual possui conteúdo, ${ }^{1}$ na medida em que os episódios sensórios de um indivíduo envolveriam a operação de capacidades conceituais que capturam um modo geral - e por isso mesmo conceitual de o mundo aparecer na experiência. Contudo, autores ditos antirepresentacionistas, como Travis $(2004 ; 2007 ; 2013)$ têm criticado posições como a de McDowell. Segundo Travis, nossa experiência do mundo seria antes uma questão de um sujeito estar em contato perceptivo com propriedades e objetos independentes da mente (mind independent), o que designaria a experiência perceptual como tendo, fundamentalmente, um aspecto de particularidade que se difere categorialmente do caráter de generalidade próprio dos nossos juízos perceptivos.

A contraposição entre estes dois autores caracteriza o chamado "Debate entre McDowell e Travis". Este artigo defenderá, em linhas gerais, o tipo de posição sustentada por McDowell em oposição a Travis. Em vistas disso, o texto terá três objetivos. Primeiramente, a título de uma apresentação e clarificação das motivações de 
posições tanto representacionistas quanto antirepresentacionistas realizarei uma reconstrução do debate entre McDowell e Travis. Em seguida, a partir de uma avaliação dos argumentos apresentados no debate pretendo identificar um impasse à primeira vista incontornável entre estes dois autores, que diz respeito, mais especificamente, à ideia que de que uma posição representacionista como a de McDowell deveria entender o conteúdo da experiência perceptual como sendo análogo ao conteúdo de nossos juízos perceptivos. Por fim, com o intuito de contornar este impasse trarei elementos vindos da tradição fenomenológica, mais especificamente da filosofia de Martin Heidegger. Tendo como ponto de partida a interpretação representacionista e conceitualista de Golob (2014) com relação ao texto heideggeriano, viso trazer Heidegger como um aliado a posições como a de McDowell, ao passo que tentarei mostrar que o modo como o filósofo alemão apresenta a noção fenomenológica de intencionalidade pode trazer uma via-média ao debate, que, por sua vez, acomode nossa posição representacionista inspirada em McDowell a certas demandas de Travis.

\subsection{Enquadramento do debate}

A experiência perceptual, sem dúvida, orienta nosso conhecimento do mundo. Seu papel epistemológico, assim, contribui para que nossos pensamentos sobre uma realidade independente sejam adequados do ponto de vista da racionalidade. Nessa perspectiva, o debate ao qual iremos nos debruçar busca, em linhas gerais, dar conta de uma questão central: como podemos estabelecer relações propriamente racionais entre experiência e juízos perceptivos. Dito de outro modo: como nossa sensibilidade a coisas que estão no mundo, como, por exemplo, o sol ou o nascer do sol explicaria o pensamento de que o sol nasceu?

Em Mente e Mundo (M\&M), McDowell, em espírito terapêutico de dissolução deste "problema" filosófico, nos convida a pressupor que a experiência perceptual ${ }^{2}$ ela mesma, assim como nossos pensamentos, possui conteúdo: ora, somente seria possível acreditar ou ajuizar que o sol nasceu se, por exemplo, vemos que o sol nasceu. O "refrão" kantiano, ao dizer que "Pensamentos sem conteúdo são vazios (...) intuições sem conceitos são cegas" (CRP, A 51, B 75), já teria nos apontado há tempos, de acordo com McDowell, que o ingresso de nossas experiências trabalha em conjunto com o entendimento enquanto faculdade própria dos juízos, o que dá à experiência, e não apenas ao pensamento, um conteúdo proposicional e por isso conceitual. ${ }^{3}$

$M \& M$ é uma obra onde McDowell toma a experiência como sendo uma atualização de capacidades conceituais ${ }^{4}$ na consciência sensível. Segundo ele, capacidades conceituais são aquelas passíveis de reconhecimento enquanto tais "apenas contra o pano de fundo do fato de que alguém que as possui é capaz de responder a relações racionais que ligam os conteúdos dos juízos da experiência a outros conteúdos ajuizáveis (McDowell 2005, p.48)". Experiências perceptuais, assim, são compreen- 
didas por McDowell como tendo um papel normativo, na medida em que forneceriam ao sujeito razões propriamente ditas às suas crenças e juízos sobre o mundo. Ainda segundo McDowell, a experiência permitiria, com efeito, que,

a própria disposição geral da realidade exerça uma influência racional sobre aquilo que um sujeito pensa (...). Que as coisas são de tal modo de tal e modo é o conteúdo conceitual de uma experiência [e] também um fato perceptível, um aspecto do mundo perceptível. (McDowell 2005, p.63. Grifo do autor)

Dessa maneira, na história contada em $M \& M$ somos apresentados na experiência a generalidades proposicionalmente estruturadas, ao percebermos que as coisas são de tal e tal modo.

Em outras palavras, isto seria nada mais que uma maneira de dizer que a experiência perceptual possui conteúdo. Este tipo de argumento - chamado de representacionista - defende, em linhas gerais, a seguinte tese: experienciar o mundo é representá-lo como sendo de algum modo. ${ }^{5} \mathrm{Na}$ medida em que nosso intuito será o de defender que a experiência perceptual possui conteúdo, precisaremos, antes disso, buscar responder às pressões antirepresentacionistas de uma figura que terá papel central em nossas discussões, a saber, Charles Travis. ${ }^{6}$ Segundo ele, o "refrão kantiano" não soaria bem a quaisquer ouvidos: experiências, além de cegas, seriam mudas.

$\mathrm{O}$ antirepresentacionismo advogado por Travis sustenta, em um ataque direto a McDowell e outros representacionistas, que a percepção não possuiria um conteúdo de que tal e tal é o caso. Por exemplo, não seria razoável, para Travis, dizer que veríamos que o sol nasceu no sentido proposto em $M \& M$, já que conteúdos proposicionais não seriam coisas pertencentes ao âmbito da sensibilidade. Ao apelar à seguinte citação de Gottlob Frege, Travis procura esclarecer sua posição:

Não vemos que o sol nasceu? E não observamos que isso é verdade? Que o sol nasceu não é um objeto que envia seus raios que atingem meus olhos, não é uma coisa visível como o sol é em si. Que o sol nasceu é reconhecido na base de impressões sensoriais. Pois tudo aquilo que é verdadeiro não é uma propriedade perceptualmente observável (Travis 2013, p.229). ${ }^{7,8}$

Em nossa visão, a constatação de inspiração fregeana de Travis se apresenta, é verdade, como um poderoso desafio a um autor como McDowell. Sem dúvida, defender que a experiência perceptual possui conteúdo proposicional não se mostra como algo defensável: não parece fazer sentido dizer que temos contato visual com proposições presentes no mundo. Após as críticas de Travis, o insucesso da tese proposicionalista de $M \& M$ foi reconhecido pelo próprio McDowell: "Charles Travis me forçou a pensar nesses casos, e, ao abandonar minha antiga suposição, estou parcialmente voltando a uma visão que ele incitou em mim" (McDowell 2009, p.259). 
De modo geral, a visão antirepresentacionista de Travis se contrapõe à ideia de que a consciência visual ${ }^{9}$ é uma questão de representar objetos independentes da mente (mind-independent objects), ou seja, de que a experiência possui conteúdo. Em termos positivos, o antirepresentacionismo de Travis propõe que o papel da percepção seria o de apresentar à consciência coisas perceptíveis como o sol ou o nascer do sol, e não o de nos colocar em contato com conteúdos proposicionais. De acordo com Travis, um juízo sobre objetos da experiência adquire seu conteúdo, de fato, $a$ partir da experiência (downstream from experience), algo também defendido pelo representacionista; isto não precisaria implicar, contudo, que a experiência ela mesma possuísse um conteúdo derivado ou idêntico ao de um pensamento. Travis nos convida, assim, a aceitar a ideia de que o conteúdo de um juízo perceptivo é, pelo contrário, explicativamente derivado da experiência, que, por sua vez, não possuiria qualquer tipo de conteúdo.

Críticas desta natureza levaram McDowell a reformular a posição proposicionalista presente em M\&M. Avoiding the Myth of the Given (AMG) inaugura aquilo que ele passou a chamar de conteúdo "intuicional" e não mais proposicional da experiência perceptual. Tal conteúdo, desta vez, seria não proposicional ainda que conceitual, em uma tentativa de acomodação de sua descrição da experiência perceptual às pressões de Travis. Apesar dos esforços de seu interlocutor, Travis (2018), em seu mais recente texto dedicado ao debate, não se deu por convencido, fato este que nos motivou a buscar fornecer uma contribuição nas tentativas de se contornar os impasses desta contenda.

Em vistas disso, nossa proposta é a de trazer elementos vindos, mais especificamente, da tradição fenomenológica, especialmente de Heidegger. Na esteira das tentativas de se colocar em conversa as chamadas tradições "analítica" e "continental" em filosofia, teremos como norte a interpretação conceitualista e representacionista de Sacha Golob, interpretação esta que vai de encontro à chamada leitura analítica dominante da filosofia heideggeriana inaugurada por Hubert Dreyfus e seguida por autores como Taylor Carman e Mark Wrathall. Isto se justifica pelo fato de que este tipo de interpretação, como veremos, nos abre um caminho para compreendermos que aquilo que se passa na experiência perceptual é irredutível aos nossos juízos perceptivos, como quer Travis, o que não excluiria a possibilidade de a percepção possuir conteúdo conceitual ainda que não proposicional, como quer McDowell.

Isto posto, seguiremos os seguintes passos: primeiramente, faremos uma mapeamento do debate a partir do argumento antirepresentacionista de Travis no contexto de suas críticas ao tipo de posição presente em $M \& M$. Em seguida, apresentaremos a chamada nova posição de McDowell, que pretende responder Travis, ao mesmo tempo que mostraremos a tréplica do último. Depois, traremos ao debate uma leitura conceitualista e representacionista da fenomenologia de Heidegger. Por fim, iremos propor como possibilidade de via média ao debate uma aproximação entre Heidegger 
e McDowell que, ainda assim, poderia se acomodar a certas demandas argumentativas de Travis.

Com isto em mente vejamos, a seguir, como Travis lança mão de seu argumento antirepresentacionista.

\section{2. $\mathrm{O}$ argumento antirepresentacionista de Travis à luz de Mente e Mundo}

O argumento antirepresentacionista de Travis presente em The Silence of the Senses, assim como o desafio a McDowell e outros representacionistas, ${ }^{10}$. costuma ser formulado de maneiras um tanto distintas. Aqui, optamos por seguir o modo como Wilson (2018) o apresenta. ${ }^{11}$

Em primeiro lugar, é essencial entendermos a qual tipo de representação Travis endereça suas críticas. Nos termos de Wilson, a representação perceptual ( $p$-representation - daqui em diante "represeentação-p") criticada por Travis difere-se de outros sentidos de representação. Por exemplo, Travis não tem como alvo a ideia de que um mapa pode representar a cidade de Londres; tampouco, que anéis numa árvore podem representar a sua idade. Travis também não nega a existência de representações subpessoais descritas pela neurociência ou pela psicologia da percepção. Assim sendo, vejamos, através de quatro condições apresentadas por Travis (2004, p.63), o conjunto de características da chamada represeentação-p, que deve ser entendida no contexto de uma noção propriamente filosófica de representação:

(i) Objetividade: A representação em questão consiste em representar as coisas enquanto tais (assim, verdadeiramente/veridicamente, ou falsamente/não veridicamente).

(ii) Valor de face: Possui, ou dá à experiência perceptiva, um valor de face, o qual pode ser aceito ou recusado (ou descontado).

(iii) Dadidade: Não é autorepresentação [represeentação pelo sujeito]. (É alorepresentação [represeentação para o sujeito], embora aqui, não de forma crucial.)

(iv) Disponibilidade: Quando somos assim representados, podemos reconhecer que, e como, isto é assim; mais pertinentemente, podemos apreciar o que é assim representado para nós como tal.

Com tais condições em mãos, temos agora uma boa oportunidade de esclarecê-las à luz do representacionismo defendido por McDowell, uma vez que as mesmas se propõem a caracterizar justamente o tipo de ideia presente em $M \& M$.

A Objetividade sugere que a represeentação-p possui condições de correção (correctnes conditions), no sentido de que uma percepção correta seria verdadeira. ${ }^{12} \mathrm{Em}$ 
$M \& M$ McDowell, sem dúvida, está comprometido com esta ideia: "algo que possui certo conteúdo é correto, no sentido relevante, apenas quando as coisas são tais como esse algo representa. Não consigo encontrar nenhuma boa razão para não chamar esta correção de 'verdade"' (McDowell 2005, p.205). Dessa maneira, a represeentação-p, por ser caracterizada como uma representação "de coisas enquanto tais" deve ser proposicionalmente estruturada, se queremos estabelecer uma relação propriamente normativa entre juízo, verdade e experiência; no linguajar de $M \& M$, por certo, o sujeito percebe que as coisas são de tal e tal modo, ${ }^{13}$ algo que serve como base para juízos.

A condição Dadidade propõe que não são apenas os juízos que possuem conteúdo conceitual: a experiência ela mesma possui o mesmo tipo de conteúdo. McDowell, na Terceira Conferência de $M \& M$, é claro a esse respeito: "Um juízo de experiência não introduz um novo tipo de conteúdo, mas simplesmente endossa o conteúdo conceitual, ou parte dele, já possuído pela experiência na qual o juízo se fundamenta" (McDowell 2005, p.85). Para ele, deveríamos pressupor que experiência perceptual seria passiva, se queremos dar conta de uma coerção daquilo é dado na experiência sobre a liberdade de nossos pensamentos. Isto quer dizer, de acordo com essa sugestão de McDowell, que a represeentação-p não é uma questão de autorepresentação, ou seja, um conteúdo resultante de uma representação pelo sujeito, como no caso de juízos e crenças, e sim de alorepresentação, na medida em que o conteúdo é dado ao sujeito na percepção.

As características condensadas na condição Valor de Face também estão presentes em $M \& M$. A ideia é que a experiência perceptual transmitiria (convey) ao sujeito um estado de coisas percebido como sendo de um certo modo, cabendo ao sujeito aceitar ou rejeitar o valor de face de sua experiência. Aceitar uma experiência em seu valor de face seria o mesmo que ajuizar que as coisas são do modo como aparecem; já rejeitar seu valor de face seria, em termos mcdowellianos, dar um "passo atrás" (step back) em uma inclinação inicial a ajuizar que uma coisa é do modo como aparece. Este seria o caso, por exemplo, de ilusões ou alucinações. A esse respeito, diz McDowell:

No mínimo, deve ser possível decidir se devemos ou não julgar que as coisas são tais como nossa experiência nos mostra como elas são. O modo como as coisas nos são dadas na experiência não é algo que esteja sob nosso controle, mas cabe a nós decidir se aceitamos ou rejeitamos as aparências. (McDowell 2005, pp.47-8)

Na medida em que o valor de face permite tanto a rejeição quanto a aceitação de um conteúdo, a representação-p só poderia ser um caso de alorepresentação, onde o sujeito é consumidor e não produtor da conteúdo de sua experiência. Ao contrário do juízo, com efeito, não podemos decidir ou escolher aquilo que percebemos em uma experiência. ${ }^{14}$ Segundo um célebre dito de McDowell em $M \& M$, na experiência sim- 
plesmente "encontramo-nos investidos de conteúdo (saddled with content)" (McDowell 2005, pp.46-7, grifo meu).

A condição Disponibilidade indica que o conteúdo de representações- $p$ deve ser passível de reconhecimento, no sentido de estar cognitivamente disponível ao sujeito a partir da aparência da experiência. Ora, representar coisas como sendo de tal e tal modo requer que a pessoa se reconheça como fazendo isto, ou seja, requer que o conteúdo da represeentação-p seja um conteúdo para o sujeito. A Disponibilidade, dessa maneira, se apresenta como uma implicação das condições Dadidade e Valor de Face: o conteúdo é dado ao sujeito na percepção, ou seja, é uma questão de alorepresentação. Além disso, devemos ter em mente que o sujeito da represeentação-p deve encontrar-se apto a apreender o modo como o mundo aparece na experiência, no sentido de ser capaz de reconhecer aquilo que faz com que sua represeentação-p seja verídica ou correta. Em $M \& M$, McDowell afirma algo exatamente nesta mesma linha, ao defender que só faz sentido falar em razões para crença de um sujeito se o mesmo reconhece estas razões como sendo suas razões, "as razões que o sujeito possui para acreditar em algo" (McDowell 2005, p.205, grifo do autor). Para ele, a condição de correção de um juízo, como vimos, é racionalmente justificada pelo modo como o mundo nos aparece na experiência, isto é, em razão da experiência perceptual correspondente: o juízo de que o sol nasceu se baseia no fato de que vemos que o sol nasceu. A condição Disponibilidade, assim, sugere que no caso da percepção visual a característica que torna possível reconhecermos o conteúdo da represeentação-p é o modo como as coisas aparecem (look). Logo, devemos entender "aparências" (looks) como aquilo que permite a alguém reconhecer os conteúdos de sua experiência, no sentido de fazer com que estes conteúdos estejam disponíveis ao sujeito.

Tendo em mente as quatro condições da represeentação-p, vamos, enfim, ao argumento antirepresentacionista de Travis.

Aquilo que é central ao argumento é a constatação de que não há qualquer sentido de ver como/que (seeing as/seeing that) e aparecer/parecer (look) adequado à experiência visual. E é importante notar que, no intuito de sustentar esta posição, Travis apresenta aqueles que seriam, supostamente, os dois únicos sentidos possíveis de aparência: as aparências evidenciais (evidentiary looks) e as aparências comparativas (comparative looks).

No caso das aparências evidenciais, o modo como um objeto ou uma cena aparece pode ser tomado como evidência para uma proposição: pode parecer que o sol nasceu, algo que também pode indicar, por exemplo, uma crença ou juízo com o mesmo conteúdo. Mas como já apontado anteriormente, aparências evidenciais não poderiam ser consideradas tipicamente visuais: que as coisas são de tal e tal modo não é uma característica da experiência perceptual visual de um sujeito. Logo, aparências evidenciais não podem sustentar a noção de representaçãop.

Antes de falarmos das aparências comparativas, é oportuno, no contexto das apa- 
rências evidenciais, ressaltar que a afirmação de McDowell de que percebemos o mundo como sendo de um certo modo implica que a experiência nos apresenta a generalidades conceitualmente estruturadas, o que permite que a experiência nos forneça razões propriamente ditas a juízos sobre a mesma. A experiência é conceitual na medida em que apresenta o mundo como sendo de um algum modo geral. Contra McDowell, Travis, como já indicado na citação de Frege, defenderá que o "nascer do sol" e "que o sol nasceu" são coisas distintas. Ao estabelecer uma linha divisória a "linha de Frege", nos termos do interlocutor de McDowell ${ }^{15}$ — Travis põe no lado esquerdo coisas particulares, o não conceitual, como o "sol" e o "nascer do sol"; do lado direito, coloca generalidades, o conceitual, como "que o sol nasceu". Já não é novidade para o leitor que as coisas do lado esquerdo são perceptíveis, ao passo que as do lado direito não o são. Desse modo, não haveria tal coisa como uma aparência evidencial, dado o aspecto de generalidade daquilo que é entretido como sendo de um certo modo, caso de estados não perceptuais como juízos e crenças.

No caso das aparências comparativas, um objeto ou cena se apresenta como possuindo uma aparência que é comparável à aparência de outros objetos ou cenas. O problema com as aparências comparativas, segundo Travis, é a sua equivocidade: uma estátua de cera do Papa Francisco parece tanto uma estátua do Papa Francisco quanto o Papa Francisco ele mesmo. Se este é o caso, não fica claro qual conteúdo é aquele associado à aparência comparativa. Além disso, não faria sentido falar aqui em correção ou incorreção, pois a estátua que imita o Papa Francisco não é de fato o Papa Francisco. A estátua parece o Papa Francisco não porque minha experiência representa a estátua como sendo o Papa Francisco: aquilo que experiência apresenta ao sujeito é uma imitação do Papa Francisco que é comparável ao Papa Francisco.

Diante do insucesso do apelo tanto às aparências evidenciais quanto às aparências comparativas, apresentamos abaixo a maneira como Wilson (2018) monta o argumento antirepresentacionista de Travis:

P1 Se as experiências visuais fossem representacionais-p, então seu conteúdo seria reconhecível em virtude de como, na experiência, as coisas aparecem perceptualmente.

P2 As aparências comparativas são incapazes de tornar o conteúdo representacionalp reconhecível, uma vez que são comparativas e então equívocas entre múltiplos conteúdos.

P3 As aparências evidenciais não são capazes de tornar o conteúdo representacionalp reconhecível, uma vez que não são totalmente perceptuais.

P4 Não há um sentido ou noção adicional de aparência que seja totalmente perceptual e capaz de tornar o conteúdo representacional-p reconhecível.

C1 (De P2 a P4) O conteúdo das experiências visuais não pode ser reconhecido com base no modo como as coisas aparecem.

C2 (de P1 a C1) Experiências visuais não são representacionais-p. (Wilson 2018, p.206) 
Dito isso, compreendemos que um dos desafios colocados ao representacionista é o de oferecer um outro sentido de ver como/que ou aparecer/parecer que não recaia sob uma das aparências indicadas por Travis, quais sejam, as evidenciais e/ou comparativas. Em outras palavras, consideramos que o defensor da ideia de que a experiência perceptual possui conteúdo deve ser capaz de demonstrar que P4 é falsa.

McDowell, diante da argumentação de Travis, procura, à sua maneira, exatamente rejeitar P4. Em outras palavras, McDowell, em sua chamada "nova posição", busca fornecer um sentido devidamente perceptual de ver como/que ou aparecer/parecer que não seja evidencial ou comparativo. A seguir, vejamos como o autor se propõe a fazê-lo.

\section{A nova posição de McDowell: conteúdo intuicional}

A chamada nova posição de McDowell (2009; 2018a; 2018b, 2019) se apresenta como o esforço deste autor na busca por uma resposta às pressões colocadas por Travis.

Em termos gerais, McDowell hoje reconhece que somente nos juízos as coisas seriam tomadas proposicionalmente; contudo, é crucial notar que ele, ainda assim, não abandonou sua posição conceitualista: a experiência, apesar de não mais possuir conteúdo proposicional, será tomada como tendo, agora, um conteúdo intuicional conceitualmente estruturado, o que nos permitiria continuar tomando a mesma como sendo base racional propriamente normativa para a formação de juízos.

Algo importante a ser esclarecido é o motivo pelo qual McDowell insiste em uma imagem conceitualista da experiência, já que sua nova posição estabelece uma diferença significativa entre o conteúdo dos juízos e o conteúdo da experiência perceptual. Há uma dupla razão para tal.

Por um lado, McDowell (2009) agora defende a ideia de que capacidades conceituais associadas a "sensíveis comuns" (common sensibles) estariam em operação na experiência perceptual. Sensíveis comuns são, por exemplo, modos de um animal, objeto, coisa etc. ocupar o espaço por meio de sua forma, posição, tamanho, movimento e assim por diante. Nesse sentido, McDowell propõe que a intuição nos tornaria capazes de reconhecer um animal como sendo um determinado tipo de pássaro através de seus modos de ocupação do espaço - por exemplo, a partir do modo como ele se locomove ao voar e saltar ${ }^{16}$. Dessa maneira, McDowell indica que conceitos de sensíveis comuns poderiam figurar como conteúdos da experiência perceptual.

A segunda razão remonta a uma leitura conceitualista da faculdade da "intuição" no contexto da filosofia kantiana, que tem como base textual certas passagens da Crítica da Razão Pura, como a seguinte: "A mesma função, que confere unidade às diversas representações num juízo, dá também unidade à mera síntese de represen- 
tações diversas numa intuição; tal unidade, expressa de modo geral, designa-se por conceito puro do entendimento" (CRP, A 79, B 104-5.). Na leitura conceitualista de McDowell, o que Kant pretenderia mostrar é que a mesma função dota a intuição e o juízo com a mesma unidade (togetherness), o que não deve ser confundido com ideia de que o juízo dá unidade à intuição. Assim sendo, a intuição não possuiria o conteúdo discursivo próprio dos juízos, mas ainda assim seria conceitual porque, segundo McDowell, "todo aspecto do conteúdo de uma intuição está presente em uma forma em que já é apropriado a ser o conteúdo associado a uma capacidade discursiva, se não for — pelo menos não ainda — realmente assim, associado" (McDowell 2009, p.264). A experiência, portanto, continuaria possuindo conteúdo conceitual porque potencialmente proposicional. A ideia é que conteúdos intuicionais forneceriam as bases para um juízo perceptivo, na medida em que experiência é tomada por McDowell (2018b) como uma oportunidade ou capacidade ao conhecimento perceptual. Nessa perspectiva, juízos perceptivos seriam atos completos da capacidade de conhecimento através da percepção, ao passo que a experiência perceptual seria um ato parcial desta mesma capacidade. Nessa perspectiva, McDowell (2019) vem insistindo que o sentido de "conceitual" do qual ele faz uso ultimamente diz respeito àquilo que possui a propriedade de ser conceitual, no sentido de que aquilo que um sujeito tem em vista na experiência não seria um mero agregado, mas uma atualização de capacidades conceituais com uma determinada unidade, como parece querer Kant ao afirmar que a mesma função do entendimento está presente na intuição e nos juízos; por exemplo, um sujeito, ao ter em vista um cubo vermelho, teria uma experiência entendida como uma atualização de capacidades conceituais que apresentam ao sujeito não apenas coisas como "vermelhidão" e "forma cúbica", mas a vermelhidão enquanto uma propriedade do cubo, o que refletiria uma unidade possuidora de um conteúdo conceitual passível de figurar numa frase do tipo "um cubo vermelho".

Travis $(2013,2018)$, contudo, não se mostrará convencido com a nova conceitualismo de seu interlocutor. E para melhor compreendermos a resposta de Travis a McDowell, voltemos, de maneira mais aprofundada, ao tema da generalidade.

Ao reafirmar a distinção entre o conceitual e o não conceitual, Travis recorre novamente a uma citação de Frege: "Um pensamento sempre contém algo que vai além do caso particular, por meio do qual ele o apresenta à consciência como caindo sob alguma dada generalidade" (Travis 2013, p.236). Para Travis, o que Frege entende como o caso particular é o que ele chama de a coisa sendo como é (being as it is). $\mathrm{Na}$ visão de Travis, O Papa Francisco sendo como ele é seria um item não conceitual que poderia ser apresentado em um pensamento como caindo sob uma generalidade do tipo estando a rezar uma missa; ou ainda, coisas sendo como elas são poderiam ser apresentadas em um pensamento como caindo sob uma generalidade do tipo coisas sendo tal que o Papa Francisco está rezando uma missa. Estes dois exemplos de gen- 
eralidade seriam expressões do pensamento de que o Papa Francisco está rezando uma missa. Os pensamentos se mostram, assim, como estando do lado conceitual da já aludida Linha de Frege; já os chamados casos particulares estariam do lado não conceitual.

Segundo Travis, o novo conceitualismo de seu interlocutor permanece, apesar dos recentes esforços de McDowell, implicando a presença de generalidade na experiência. Mas se isto é o caso, a nova posição de McDowell continuaria insustentável, na medida em que não é capaz de mostrar como a experiência nos apresenta aos objetos particulares essenciais para que nossos juízos sobre a mesma sejam verdadeiros. Para Travis, aquilo que torna verdadeira uma proposição empírica do tipo "esta flor tem cinco pétalas" é o modo particular e mais básico de um estado do mundo não repetível: "esta flor tem cinco pétalas" que podem ser azuis, vistas de cima, na manhã de hoje etc. No vocabulário mais recente de Travis, a experiência nos coloca em contato com o histórico (the historical) ${ }^{17}$, isto é, nos abre a uma realidade particular que dá as bases para uma proposição empírica. Se conceitos são sempre gerais, McDowell, então, erra logo de saída, ao trazer generalidade para o âmbito da particularidade.

McDowell (2018a), em resposta a Travis, pretende esclarecer sua nova posição inaugurada em $A M G$. Segundo McDowell, seu atual conceitualismo não seria uma defesa da ideia de que, na experiência, estaríamos em contato perceptual com proposições, "proto" proposições ou mesmo conceitos (a não ser, claro, aqueles relativos aos sensíveis comuns). Os objetos da experiência seriam, assim como quer Travis, coisas ordinárias como o sol, o Papa Francisco ou uma flor de cinco pétalas. Seu novo conceitualismo seria antes uma defesa de que o modo como somos abertos a estes objetos na experiência perceptual se dá por vê-los como sendo do modo como eles são. O conteúdo da experiência continua sendo conceitual não porque estamos em contato perceptivo com conceitos propriamente ditos, e sim porque o modo pelo qual um objeto é percebido é também o modo pelo qual ele pode ser ajuizado. Do contrário, aquilo que é dado na experiência não poderia servir de razão propriamente normativa para um pensamento, ideia esta que já se encontrava presente no então conceitualismo proposicional de $M \& M$.

O que devemos ter em mente é que o novo conceitualismo - agora intuicional - defendido por McDowell continua sugerindo que os objetos nos são dados na percepção de modo a serem vistos como sendo de algum modo geral:

Em uma intuição visual de um objeto, o entendimento - a faculdade dos conceitos - unifica as apresentações visuais de modos visualmente sensíveis em que o objeto é em uma apresentação do objeto no qual ele é apresentado como sendo desses modos. (McDowell 2018a, p.30)

Mas para melhor entendermos este tipo de ideia de tom evidentemente kantiano, precisamos também compreender o modo como o interlocutor de Travis lê Frege, 
este último sendo, nas palavras de McDowell, "um bom, embora claramente não acrítico, kantiano", mais especificamente no que diz respeito ao que chamaremos de questão da gramática da percepção.

Para McDowell, a leitura que Travis faz de Frege, no que concerne aos casos particulares, seria equivocada do ponto de vista gramatical. Por exemplo, "sendo" em "O Papa Francisco sendo como ele é", segundo McDowell, deveria invariavelmente possuir a forma da cópula, e, consequentemente, seria similar a "coisas sendo como elas são". Dessa maneira, "O Papa Francisco sendo como ele é" possuiria a forma lógica de uma proposição, isto é, a forma lógica de um pensamento. Ainda de acordo com McDowell, a gramática de "O Papa Francisco sendo como ele é" seria do mesmo tipo de "coisas sendo tal que o Papa Francisco está rezando uma missa". Travis teria errado ao não se dar conta de que, em termos gramaticais, não seria legítimo colocarmos em lados opostos da linha que divide pensamentos de um lado e itens não conceituais de outro coisas como "O Papa Francisco sendo como ele é" e "coisas sendo tais que o Papa Francisco está rezando uma missa".

Nesse sentido, McDowell nos convida vislumbrar uma possibilidade desconsiderada por Travis, qual seja, a de Frege aceitar a ideia de que thinkables ${ }^{18}$, apesar de não serem sensíveis à percepção, ainda assim poderiam ser conteúdo da experiência, dado o modo como somos apresentados aos objetos na percepção. É dessa maneira que McDowell se considera livre para rejeitar P4:

A distinção de Frege implica apenas na conclusão (...) de que thinkables não são objetos da consciência sensível. Thinkables podem ainda ser conteúdos da consciência sensível. A distinção nos deixa livres para sustentar (...) que a nossa percepção sensorial de objetos faz com que a racionalidade de juízos sobre eles seja inteligível em virtude do fato de que alguns modos que os objetos são são dados (ways objects are are given) em nossa própria consciência sensível. (McDowell 2018a, p.35)

A ideia central desta afirmação remonta a uma proposta já presente em $M \& M$ : a experiência perceptual é passiva, ou seja, um caso de alorepresentação. No texto de 1994, McDowell, no intuito de blindar sua posição a quaisquer acusações de idealismo, traz a noção de thinkables para estabelecer uma diferença entre pensamentos entendidos como conteúdos pensáveis (fatos seriam conteúdos pensáveis verdadeiros, por exemplo) e pensamentos entendidos como atos de pensar (juízos, por exemplo). Se a nova posição de McDowell não mais entende thinkables enquanto proposições passíveis de serem percebidas, thinkables ainda assim poderiam fazer parte do conteúdo de nossa consciência perceptual, se os entendemos como aquilo que figura enquanto um modo de um objeto ser apresentado na experiência.

Travis (2018), contudo, questiona esta resposta dada por McDowell. Segundo Travis, a suposta coincidência gramatical apontada por seu interlocutor traz o risco 
de perdermos o ponto destacado por Frege, qual seja, o de que existem duas consciências distintas, uma consciência (awareness) perceptual, outra proposicional ${ }^{19}$. McDowell, nesse sentido, não teria sido capaz de demonstrar que o modo como um objeto aparece é análogo ao modo como é entretido em um juízo. Travis aponta para a ideia de que, segundo Frege, o movimento que vai da consciência perceptual à consciência proposicional seria transcategorial, já que as relações entre conceitos seriam de uma natureza distinta daquelas em que estão envolvidos os objetos de nossa consciência perceptual: "(...) o que pode formar imagens em retinas ou filmes, vibrar tímpanos ou ser gravado etc. não é o tipo de coisa a permanecer [em relações de inferência] (...). Pois não é o tipo de coisa que seja verdadeira ou algo assim" (Travis 2018, p.42). Dessa maneira, a distinção é categorial porque os tipos diferentes de consciência não podem cair ao mesmo tempo nos lados esquerdo e direito da "Linha de Frege". A generalidade, assim, seria um modo de diferentes casos (localizados historicamente, nos termos de Travis) compartilharem algo em comum.

Nesse contexto, de acordo com Travis - e isto é um ponto crucial para esta que se apresenta como sua mais recente resposta a McDowell - alguns pensamentos se decompõem, fazendo assim com a que verdade atue sob (turn on) um dado objeto, sob um modo de um objeto ser. Esta ideia, que mais uma vez se apresenta como herdeira de Frege, sugere que pensamentos inteiros (whole thoughts) vêm primeiro, no sentido de que um e o mesmo pensamento seria passível de ser decomposto em diferentes elementos. Por exemplo, o pensamento de que o Papa Francisco reza e o pensamento de que o conceito de rezar se aplica ao Papa Francisco contariam como um e o mesmo pensamento, já que possuiriam o mesmo conteúdo, no caso, aquilo que há para se pensar, a despeito de suas diferentes estruturas. Na esteira de que pensamentos inteiros vêm primeiro, uma sentença como "a folha tem cinco pétalas" - uma instanciação que, como apontado acima, pode ocorrer de várias maneiras - contribui, segundo Travis, para o reconhecimento de qual pensamento está sendo expresso, ao tornar reconhecível algum objeto sob o qual, em alguma decomposição do pensamento, a verdade pode atuar: para a o pensamento ser verdadeiro, é para a coisa ser de um certo modo, isto é, ser como é representada.

Diante disso, é importante notar que o impasse entre Travis e McDowell se dá, de modo geral, nos seguintes termos.

Para McDowell, a passagem do não conceitual ao conceitual é ilegítima, sob pena de não ser possível estabelecermos uma conexão propriamente normativa entre pensamento e experiência perceptual. É uma exigência que somente conteúdos análogos em sua forma possam estabelecer relações propriamente racionais entre si. A gramática dos juízos e da percepção seria, assim, de mesmo tipo, uma vez que conteúdos conceituais, ainda que não proposicionais, poderiam figurar na experiência perceptual, como teria indicado Kant ao afirmar que a mesma função do entendimento se encontraria em operação também na intuição. Tais conteúdos, segundo 
McDowell, não seriam, dessa maneira, um caso de autorepresentação, já que conceitos estariam passivamente em operação na entregas da sensibilidade. Em vistas disso, ele entende ser possível contornar as pressões de Travis, na medida em que tanto o não proposicional quanto o proposicional seriam modos conceituais de consciência, e dado que o mesmo modo de unificação presente nos juízos se encontraria também na experiência perceptual. Sendo a experiência perceptual de natureza conceitual, McDowell se mostra comprometido com a ideia de que a mesma deva possuir conteúdo, dada a estrutura de unificação própria dos juízos, o que o coloca ao lado de posições representacionistas no debate.

Travis, por sua vez, afirma reiteradamente que a experiência perceptual não possui qualquer tipo de conteúdo. Seu argumento, com efeito, procura colocar uma pressão em posições como a de McDowell, ao estabelecer uma distinção propriamente categorial entre pensamento e sensibilidade. Para Travis, aquilo que possui um caráter de generalidade (o conceitual) não é passível de ser percebido. Experiências perceptuais, ao contrário, nos colocam em contato com o particular, com aquilo que, no máximo, apenas pode instanciar algum modo geral de uma coisa ser em um pensamento. Se o implausível proposicionalismo presente em $M \& M$ foi abandonado, McDowell estaria ainda hoje preso ao "dogma" de que o único modo de provar algo seria através da transmissão de uma verdade a partir da experiência perceptual, o que o permaneceria levando ao erro de incluir conteúdos conceituais, ainda que intuicionais, na experiência.

Diante disso, a próxima seção busca trazer novos elementos, no intuito de abrir diferentes caminhos com vistas a encontrar saídas - ou no mínimo uma via média - aos aspectos que parecem como que travar o debate entre McDowell e Travis. Para tal, colocaremos em cena um importante pensador da tradição fenomenológica: Heidegger.

\section{Fenomenologia heideggeriana, conceitos e as quatro condições da representaçãop}

A presente seção, em linhas gerais, procura trazer contribuições às tentativas de se colocar em conversa as chamadas tradições "analítica" e "continental" em filosofia. Neste tipo de empreitada, se insere um grupo de filósofos e comentadores que pretendem se apropriar de aspectos da filosofia de Heidegger para dar conta de problemas tipicamente abordados pela filosofia analítica. Na esteira da leitura heideggeriana inaugurada por Dreyfus (1991), autores como Carman (2003), Wrathall (2011) entre outros se propõem a colocar o filósofo alemão em diálogo com tradição angloamericana em filosofia. Sacha Golob, com efeito, também se encontra nesse grupo. Mas apesar desta característica em comum, algo crucial que irá diferenciar Golob dos 
autores acima mencionados é o modo como interpretam um determinado aspecto da filosofia heideggeriana que parece ser ponto pacífico entre eles, a saber, a ideia de que o denominado nível mais básico de intencionalidade tal qual descrito por Heidegger possui estrutura não proposicional. Se, por um lado, a chamada leitura analítica dominante influenciada por Dreyfus entende este nível mais básico de intencionalidade como não envolvendo conceitos, Golob - e isto naturalmente será importante aos nossos propósitos - defenderá, ao contrário, que o mesmo o mesmo possui conteúdo conceitual. $^{20}$

Teremos como ponto de partida, justamente, a interpretação conceitualista de Heidegger inaugurada por Golob em seu livro Heidegger on Concepts, Freedom and Normativity, de 2014. Por um lado, isto se deve ao fato de Golob sugerir que Heidegger entende que a percepção, assim como os juízos, seria um veículo de entrega de conteúdos conceituais. O que diferencia estes dois veículos seria a estrutura gramatical de cada um: conteúdos proposicionais, próprios dos juízos, envolveriam a cópula (a é b); já conteúdos da percepção possuiriam uma gramática conceitual mas não proposicional, que envolve o "como" (a como b). Por outro, também se justifica por este autor recomendar uma interpretação em que Heidegger pode ser visto como comprometido com a ideia de que a experiência perceptual possuiria condições de correção, o que designaria o filósofo alemão como defendendo, nos termos de Golob, um certo tipo de representacionismo.

Já de maneira mais específica, esta seção pretende trazer aspectos da filosofia de Heidegger para o interior do debate entre representacionistas e antirepresentacionistas, a fim de ampliarmos o leque argumentativo em favor do tipo de representacionismo defendido nos termos de McDowell, ou seja, que entende conteúdos não proposicionais como, ainda assim, envolvendo conceitos. Se Golob nos traz um argumento a ser utilizado em defesa de uma leitura conceitualista e representacionista de Heidegger contra a aqui denominada leitura dominante, pretendemos, para além disso, reunir elementos capazes de sustentar uma posição representacionista que contemple as quatro condições da representaçãop e que seja uma candidata à rejeição de P4, ao mesmo tempo em que se acomode à pressão colocada por Travis de que há uma diferença genuína entre o que se passa na experiência e nos juízos, algo que o filósofo alemão, como veremos, também procura defender. Em vistas disso, lançaremos mão de uma apropriação da ideia heideggeriana de que o significado encontra-se articulado já na própria experiência, o que nos abre um caminho para sustentar que o significado, assim como os thinkables mcdowellianos, pode ser conteúdo da experiência, ainda que não em um sentido perceptivo. Desse modo, esperamos, em favor de uma posição representacionista, contornar o impasse entre McDowell e Travis descrito no final da Seção 3.

Antes de tratarmos propriamente dos temas da gramática da percepção e da representação no interior da filosofia heideggeriana, é necessário esclarecermos um im- 
portante conceito para a tradição fenomenológica, a saber, o de intencionalidade. Isto será crucial, inclusive, tanto para aproximarmos ao máximo a terminologia heideggeriana do debate analítico contemporâneo em torno da natureza filosófica da percepção quanto para esclarecermos e delimitarmos as diferenças entre leituras conceitualistas e não conceitualistas em relação a Heidegger.

O termo "intencionalidade" diz de um estado mental (crença ou juízo, por exemplo) que ele é sobre ou direcionado a algo. De acordo com Heidegger, deveríamos entender também a percepção como possuindo uma estrutura intencional:

O que chamamos concisamente de percepção é, mais explicitamente formulado, o direcionamento perceptivo de si mesmo para o que é percebido (...) Esse direcionamento constitui, por assim dizer, a estrutura de todo o fenômeno 'percepção'. (...) Essa relação expressamente percebida de perceber com o percebido também pertence a outros modos de comportamento: à mera representação, que se relaciona com o representado, ao pensar, que pensa o pensamento, ao juízo, que determina algo ajuizado, ao amor, que se relaciona com um amado. (...) A fenomenologia chama essa estrutura de intencionalidade. Todo comportamento é um comportamento-em-direção-a; percepção é uma percepção-de (Heidegger 1982, p.57-8)

Mesmo sendo a intencionalidade, para Heidegger, uma estrutura comum tanto ao pensamento quanto à percepção, é importante notar que o autor buscou estabelecer uma diferença fundamental entre aqueles que seriam dois níveis de intencionalidade: um mais básico e primordial, onde o indivíduo interage com o mundo de maneira irrefletida, ateórica e atemática, e outro no qual o indivíduo se engaja com o mundo de modo proposicional. O célebre exemplo da atividade de martelar descrito em Ser e tempo (Heidegger 2012, p.213) busca, justamente, delimitar estes que seriam dois modos de intencionalidade. Em uma atividade onde o martelo não apresenta qualquer defeito ou mau funcionamento, ou o martelar se dá sem perturbações de qualquer natureza, nos encontraríamos em um modo de experiência irrefletido e não proposicional; se algo dá errado no martelar — por exemplo, se o martelo se apresenta como mais pesado que o de costume - somente aí passamos a evidenciar aspectos predicativos por meio de juízos do tipo "o martelo [está] muito pesado" (Heidegger 2012, p.443). Teríamos, assim, dois modos de intencionalidade: um mais básico e não proposicional, próprio de nossas atividades práticas no mundo, e outro derivado e proposicional, próprio de nossos engajamentos em juízos sobre o mundo.

Como já indicado acima, a leitura analítica dominante da filosofia de Heidegger o considera um autor não conceitualista. Carman (2003), por exemplo, sugere que se nosso engajamento prático com o mundo é não proposicional ele seria, consequentemente, não conceitual. Esta conclusão, à primeira vista, se mostra como bastante natural, na medida em que conteúdos proposicionais invariavelmente envolvem con- 
teúdos conceituais. Contudo, entendemos que este poderia ser um passo apressado: seguindo Golob e sua interpretação conceitualista de Heidegger, compreendemos que apesar de o proposicional ser suficiente à intencionalidade conceitual ele não seria necessário.

Ainda que Heidegger afirme, de fato, que as intencionalidades não proposicional e proposicional seriam irredutíveis, Golob propõe que cada uma delas não deveria ser tomada como possuindo, respectivamente, estrutura não conceitual e conceitual. Segundo Golob, aquilo que as difere seria antes suas respectivas gramáticas e, assim, o modo como articulam conteúdos propriamente conceituais. No exemplo a seguir, Golob procura esclarecer o que está em jogo:

"Posso dizer em inglês que a escola fica à beira do lago. Também posso fazer
isso usando outra linguagem natural ou artificial que pode, por exemplo, não
possuir estrutura sujeito-predicado. Também posso fazer isso desenhando
um tosco mapa. Faz razoável sentido dizer que, em cada caso, você esteja
recebendo a mesma informação; mas a gramática, os mecanismos de en-
trega pelos quais essas informações são transmitidas e articuladas, diferem
claramente. (Golob 2014, p.103)

Nessa perspectiva, a sugestão de Heidegger, segundo Golob, seria a de que conteúdos proposicionais compreendem uma estrutura gramatical que envolve o "é" (do tipo "a é b"), ao passo que conteúdos não proposicionais possuiriam uma estrutura gramatical que envolve o "como" (do tipo "a como b"). Mas se este é o caso, por quais razões a chamada estrutura-"como" (Als-Struktur) heideggeriana seria ao mesmo tempo não proposicional e conceitual?

Segundo Golob, uma destas razões surge do caráter normativo deste nível de intencionalidade mais básico descrito por Heidegger. A fenomenologia heideggeriana propõe que a localização de um objeto físico se dá através de aspectos contextuais que nos permitem dar a esse mesmo objeto o seu significado. Em um determinado contexto ${ }^{21}$, um objeto deixaria de ser simplesmente uma entidade física bruta - no caso de uma cadeira, por exemplo, um mero objeto de madeira — ganhando, com isso, liberdade para deixar se envolver compreensivamente em uma cadeia significativa de remissões, que abrange um aspecto tanto relacional (composto por escritório, mesa, sala de jantar etc.) quanto teleológico (fazer uma refeição, confraternizar e assim por diante). O mundo tal qual entendido por Heidegger permitiria que as coisas, assim, se apresentassem como significativas, uma vez que é o significado aquele componente que contextualiza nossa experiência. Por esse ângulo, a variável "b" da estrutura "a como b" seria responsável por fornecer o significado através do qual a variável "a" é compreendida. Aqui, é possível percebermos o caráter holístico das relações contextuais, que parecem requerer, mesmo em nossas experiências mais ordinárias, que sejamos capazes de compreender normativamente aquilo que circunscreve o significado em um determinado contexto. Por exemplo, usar adequadamente um martelo 
não requer um exercício judicativo - um apelo a uma proposição do tipo "isto é um martelo, que serve para tais e tais usos, e não serve para outros"; não obstante, compreender as relações contextuais nas quais este objeto está envolvido demandaria uma compreensão normativa em sentido forte (e por isso conceitual) de seu significado: martelos servem para, ou nos autorizam a, tais e tais usos, o que exige que tenhamos também uma compreensão de que os mesmos não servem, no contexto social em que vivemos, para outros usos, algo que indicaria que a estrutura "a como b", apesar de não proposicional, compreenderia um modo de experienciar o mundo ainda assim conceitual.

Ainda de acordo com Golob (2014, p.90), sugerimos que outra razão para a natureza não proposicional mas conceitual da estrutura "a como b" vem do fato de Heidegger fenomenologicamente descrever nossa abertura a um mundo já dotado de significado, onde aspectos de generalidade se encontrariam neste que seria o nível mais básico de intencionalidade explicitado pela estrutura "a como b". Nesta passagem de Ser e tempo, podemos notar a presença de generalidade em nossa experiência perceptual:

'De imediato' nunca ouvimos barulhos e o conjunto de ruídos, mas o carro que range, a motocicleta. [Não nos encontramos] de modo algum imediatamente juntos a sensações, cuja concatenação tivesse primeiramente de ser formada para que se proporcionasse o trampolim a partir do qual o sujeito saltaria para alcançar finalmente um 'mundo'. (Heidegger 2012, p.461-3)

Aqui, podemos observar, segundo Heidegger, que na percepção encontramos algo que já é articulado como algo, uma vez que o mundo já é pressuposto em termos de seu significado. Este modo de abertura ao mundo seria, assim, condição de possibilidade da intencionalidade, mesmo daquela que se dá no nível mais básico, próprio da percepção. Em descrições como essa, vemos que conceitos como "carro" e "motocicleta" são apresentados como articulados já no próprio âmbito perceptivo. Nosso acesso perceptivo compreenderia, dessa maneira, um aspecto de generalidade, ainda que isto se dê de modo não proposicional: perceber um som como sendo de uma motocicleta não requer qualquer engajamento prévio em juízos. Aquilo que distingue modos não proposicionais e proposicionais de intencionalidade, como vimos, não é a ausência de conteúdos conceituais no nível não proposicional de intencionalidade: um e o mesmo conceito é articulado de modos distintos tanto na estrutura "a como b" quanto na estrutura "a é b". Como no caso do martelar, o que Heidegger parece nos querer chamar atenção é para a afirmação de que modos proposicionais não têm prioridade sobre modos não proposicionais: "A proposição 'a é b' não seria possível (...) se ela não pudesse surgir a partir da experiência subjacente do 'a como b'" (Heidegger, 2011, p.385); isto não comprometeria, no entanto, a ideia de que o conceito "martelo" figura, ainda que por meio de articulações distintas, nos dois níveis de intencionalidade. 
$\mathrm{Na}$ esteira do que foi dito até agora a respeito da estrutura "a como b", daremos um passo para aquela que seria uma interpretação de Heidegger que o entenderia, em termos bastante específicos ${ }^{22}$, como um representacionista, uma vez que, em nossa busca por uma rejeição à $\mathrm{P} 4$, entendemos que a variável "a" da estrutura -"como" nos ajuda a esclarecer a posição de Heidegger com respeito ao debate contemporâneo entre representacionistas e antirepresentacionistas.

É importante notar que este tipo de leitura entende a variável "a" como sendo o objeto ele mesmo, assim como exige Travis, o que não precisaria implicar, entretanto, que a experiência não possua conteúdo. Aqui, a posição de Heidegger poderia ser identificada com uma espécie de representacionismo, na medida em que a variável "a", no interior da explicação da estrutura-"como", não seria uma entidade bruta, uma vez que a experiência desta entidade, em termos heideggerianos, possuiria condições de correção: o objeto ele mesmo é considerado normativamente em termos de seu significado. A variável "a", então, é compreendida no interior de um contexto normativo relevante em uma dada experiência, algo que ocorre não apenas no pensamento, como indica Travis, mas na própria experiência perceptual, como querem autores como McDowell.

Tendo este pano de fundo teórico em mãos, pretendemos, a seguir, mostrar em que medida uma proposta fenomenológica desta natureza poderia nos dar boas razões para satisfazermos as condições Objetividade, Valor de Face, Dadidade e Disponibilidade.

Ainda que a condição Objetividade, no modo como é descrita em The Silence of The Senses, diz da representaçãop que ela deva ser uma "representação de coisas enquanto tais", isto é, possuidora de conteúdo proposicional, entendemos que o desenvolvimento dos argumentos de McDowell e Travis desde então abre a possibilidade de conteúdos não proposicionais entrarem na disputa, dado o modo como McDowell apresenta sua nova posição e pelo fato de Travis, diante disso, ter também reformulado suas críticas. Além do mais, vimos que Travis tem como adversários não apenas "o" McDowell de $M \& M$, mas também autores não conceitualistas e, consequentemente, não proposicionalistas, que defendem que a experiência é uma questão de representação (ver nota 12). Nessa perspectiva, entendemos que o conteúdo não proposicional mas conceitual do nível mais básico de intencionalidade tal qual descrito por Heidegger pode figurar como candidato a preencher os requisitos da condição Objetividade.

Dito isso, nossa aposta é a de que o tipo de normatividade envolvido no nível mais básico de intencionalidade pode indicar que a experiência perceptual possui condições de correção, no sentido de uma determinada prática ou percepção ser passível de adequação ou inadequação em um dado contexto onde a variável "a", por meio da variável "b", é compreendida. No que diz respeito à questão da verdade ou falsidade da representaçãop, a estrutura "a como b”, assim como os conteúdos 
intuicionais propostos por McDowell, também possuem um caráter normativo. Nos termos de McDowell, um conteúdo intuicional nos fornece razões para juízos sobre a experiência; já Heidegger, analogamente, parece indicar que é condição de possibilidade para um juízo do tipo "a é b" que um indivíduo já tenha experienciado a variável "a" enquanto previamente inserida em um contexto normativo, que nos permite comparar juízos e uma experiência prévia, ainda que não proposicional, de "a como b". Segundo ele, com efeito,

A estrutura-'como', a percepção prévia e formadora de unidades de algo como algo, é a condição de possibilidade para a verdade e a falsidade do $\lambda o ́$ ro 5 . Já preciso ter tido em vista o quadro-negro como algo uno, para poder expor (...) o percebido no interior do juízo. (Heidegger 2011, p.403, grifo do autor)

Assim, entendemos que a proposta heideggeriana satisfaz a condição Objetividade, na medida em que conceitos, ainda que de modo não proposicional, podem ser conteúdos da experiência.

Na esteira daquilo foi dito por nós quanto à estrutura-"como" e sua relação com os juízos, entendemos que condição Dadidade também poderia ser satisfeita em termos fenomenológicos. Em primeiro lugar, porque juízos perceptivos não introduzem um outro tipo de conteúdo; isto é, tanto a forma da cópula quanto a estrutura do "como" possuiriam conteúdo conceitual. Além do mais, entendemos que a diferença entre o "é" e o "como" não implica uma distinção entre conteúdos conceituais. Como aponta Golob, a diferença entre a estrutura "a como b" e a estrutura "a é b" é antes gramatical, ou seja, uma distinção entre os mecanismos de entrega de seus conteúdos conceituais. Por exemplo, o conteúdo de uma canção $x$ poderia entregar uma mesma informação de diferentes modos: através de uma partitura, tablatura, caixa de som ou mesmo por meio da atividade prática de um músico. Uma performance musical, assim, demonstraria de forma prática aquilo que a partitura informa em termos teóricos: a mesma canção $x$. Desse modo, uma atividade prática poderia ser entendida como um mecanismo de entrega de conteúdos conceituais, se desvinculamos o proposicional do conceitual.

Já no que diz respeito ao caráter de alorepresentação da representaçãop, uma proposta fenomenológica como a de Heidegger parece naturalmente preencher a condição Dadidade. Ora, se o autor afirma que juízos ocorrem apenas de maneira derivada da intencionalidade mais básica da percepção isto implica que a representaçãop não seria um caso de autorepresentação. Desse modo, se a representaçãop envolve nada além dos mesmos conceitos que poderiam figurar em um juízo, entendemos que a mesma seria um caso de alorepresentação, uma vez que, de acordo com a estrutura-"como", o conteúdo estaria dado ao sujeito na própria percepção, como sugere a ideia heideggeriana de que nossa abertura perceptiva ao mundo se dá de modo já significativo ainda que não proposicional. 
Quanto à condição Valor de Face, é importante notar que Heidegger não aborda em profundidade os temas da ilusão ou da alucinação ${ }^{23}$. Contudo, entendemos que o modo como a estrutura "a como b" fornece as bases para um juízo "a é b" nos ajuda a vislumbrar a possibilidade de a representaçãop, nos termos de Heidegger, preencher a condição Valor de Face. Em nossa visão, na medida em que a estrutura-"como" indica que a experiência de algo como algo é condição de possibilidade do juízo, a possibilidade do "passo atrás", como indica McDowell, poderia figurar de maneira potencial na conteúdo da experiência perceptual. Ora, se o exercício do passo atrás se dá por meio de juízos, a estrutura-"como" pode ser entendida aqui como envolvendo a operação de capacidades conceituais. Dessa maneira, na medida em que a estrutura "a como b" serve de base para o juízo "a é b" é possível concluir que há uma relação propriamente racional, e por isso normativa, entre experiência e juízo, relação esta que envolve a possibilidade de revisão por meio de uma avaliação crítica de um determinado conteúdo.

No caso da condição Disponibilidade, entendemos que a estrutura-"como" é capaz de tornar disponível um conteúdo passível de reconhecimento exclusivamente a partir da experiência, isto é, sem a entrada de qualquer autorepresentação. A variável "b" faz com que um conteúdo esteja cognitivamente disponível a partir do modo como experienciamos o mundo, ou seja, em termos de seu significado. Como é possível observar por meio da condição Objetividade, a percepção de algo como algo tornaria possível reconhecermos aquilo que faz com que uma representaçãop seja verdadeira ou falsa, a partir de suas condições de correção e adequação: um juízo "a é b" tem como base uma experiência de "a como b". Se a variável "b" é o componente que permite reconhecer, na própria experiência, o significado da variável "a", a estrutura "a como b" seria capaz de fazer com que seus conteúdos estivessem disponíveis ao sujeito da experiência.

Com base em nossa avaliação do modo como a fenomenologia heideggeriana abarcaria as quatro condições da representaçãop, conceitos poderiam, em nossa visão, ser conteúdos da experiência perceptual, se os entendemos como ingredientes que permitem termos contato perceptual com um mundo já significativo. Isto não precisa querer dizer, contudo, que temos contato perceptivo com significados, o que não excluiria a ideia de que percebemos as coisas no mundo em termos de seus significados. Consideramos, pois, que esta descrição da intencionalidade perceptual feita por Heidegger pode ser uma candidata a outro sentido de ver como que não aqueles descartados por Travis em seu argumento central, abrindo, dessa maneira, um outro caminho para se rejeitar $\mathrm{P} 4$, caminho este que possui semelhança com a ideia mcdowelliana de que thinkables, apesar de não serem coisas pertencentes ao âmbito da sensibilidade, podem ser conteúdos da experiência perceptual. Heidegger, assim como McDowell, poderia ser lido como abrindo a possibilidade, recapitulando P4, de um "sentido ou noção adicional de aparência que seja totalmente perceptual e capaz 
de tornar o conteúdo representacional-p reconhecível": ouvir um som como sendo de uma motocicleta nos permite reconhecer o mesmo como sendo tal.

Além do mais, entendemos que a estrutura-"como" poderia, em certo sentido, possuir uma vantagem explicativa em relação aos conteúdos intuicionais descritos por McDowell, uma vez que a busca heideggeriana por uma distinção irredutível entre o não proposicional e o proposicional abre também caminho para uma via média entre as posições de McDowell e Travis, na medida em que a diferença gramatical aqui discutida busca permitir a presença de conteúdos conceituais na experiência, mas de uma maneira em que há uma diferença genuína, como quer Travis, entre aquilo que ocorre nos níveis da experiência e do pensamento.

Concluímos, de qualquer modo, reiterando que nossa tentativa de contribuição ao debate não tem a pretensão de trazer uma resposta definitiva. Contudo, compreendemos que a fenomenologia de Heidegger pode, no mínimo, trazer mais elementos para serem discutidos no debate entre representacionistas e representacionistas, ao tomar especificamente a normatividade da intencionalidade não proposicional como algo que, ao menos a princípio, não aponte para qualquer analogia com o juízo, analogia esta que, como vimos, McDowell busca incessantemente e que Travis também parece assumir como sendo o cerne do debate em questão.

\section{Considerações finais}

O presente texto buscou defender uma posição representacionista e conceitualista a respeito da experiência perceptual. Ao reconstruirmos o chamado debate entre John McDowell e Charles Travis, procuramos, primeiramente, apresentar e confrontar criticamente posições representacionistas e antirepresentacionistas em torno de abordagens filosóficas a respeito da experiência perceptual. Em seguida, diante de um impasse identificado entre estes dois interlocutores, também buscamos nos utilizar de elementos da fenomenologia de Heidegger, para, de maneira argumentativa, tentar dar conta de dois objetivos específicos: por um lado, fornecer uma resposta representacionista a Travis; por outro, oferecer uma via média que, em alguma medida, acomode as posições de Travis e McDowell.

\section{Referências Bibliográficas}

Brewer, B. 2011. Perception and its Objects. Oxford University Press.

Brewer, B. 2019. Empirical reason: Questions for Gupta, McDowell, and Siegel. Philosophical Issue 29(1): 311-323.

Brogaard, B. 2015. Perceptual Reports. In: M. Matthen (ed.), The Oxford Handbook of Philosophy of Perception. Oxford: Oxford University Press. 
Byrne, A. 2001. Intentionalism Defended. Philosophical Review 110(2): 199-240.

Campbell, J. 2002. Reference and Consciousness. Oxford: Clarendon Press.

Carman, T. 2003. Heidegger's Analytic. Cambridge. Cambridge University Press.

Casanova, M. 2010. Compreender Heidegger. Petrópolis: Editora Vozes.

Dennis, P. 2012. Was Heidegger a Nonconceptualist? Ratio 25(1): 108-17.

Dreyfus, H. 1991. Being-in-the-World: A Commentary on Heidegger's Being and Time, Division I. Cambridge: MIT Press.

Drummond, J. 1990. Husserlian Intentionality and Non-Foundational Realism: Noema and Object. Dordrecht: Kluwer.

Fish, W. 2009. Perception, Hallucination, and Illusion. Oxford: Oxford University Press.

Føllesdal, D. 1969. Husserl's Notion of Noema. Journal of Philosophy 66(20): 680-687.

Frege. G. 1984 [1918-1919]. Der Gedanke. Eine Logische Untersuchung. In: Beiträge zur Philosophie des deutschen Idealismus, pp.58-77. Trans. P. Geach and R. Stoothoff. Oxford: Blackwell.

Gersel, J. 2018. The Travis-McDowell Debate. In: J. Gersel; R. Thybo Jensen; M. Thaning Sørensen \& S. Overgaard (ed.), In the Light of Experience - Essays on Reasons and Perception, p.23-35. Oxford: Oxford University Press.

Golob, S. 2014. Heidegger on Concepts, Freedom and Normativity. Cambridge: Cambridge University Press.

Heidegger, M. 1982. The Basic Problems of Phenomenology. Trans. A. Hofstadter. Bloomington: Indiana University Press.

Heidegger, M. 2011. Os Conceitos Fundamentais da Metafísica: Mundo, Finitude, Solidão. 2ª edição. Trad. M. A. Casanova. Rio de Janeiro: Forense Universitária.

Heidegger, M. 2012. Ser e Tempo. Trad. F. Castilho. Campinas: Editora da Unicamp; Petrópolis: Editora Vozes.

Kant, I. 2015. Crítica da Razão Pura. 4ํe edição. Trad. F. C. Mattos. Petrópolis: Vozes; Bragança Paulista: Universitária São Francisco.

Martin, M. G. F. 2004. The Limits of Self-Awareness. Philosophical Studies 120: 37-89.

McDowell, J. 2005 [1994]. Mente e Mundo. Trad. J. V. G. Cuter [Mind and World]. Aparecida: Ideias e Letras.

McDowell, J. 2009. Avoiding the Myth of the Given. In: Having the World In View: Essays on Kant, Hegel and Sellars, pp.256-72. Cambridge: Harvard University Press.

McDowell, J. 2018a. Travis on Frege, Kant and the Given: Comments on 'Unlocking the Outer World'. In: In: J. Gersel; R. Thybo Jensen; M. Thaning Sørensen \& S. Overgaard (ed.), In the Light of Experience - Essays on Reasons and Perception, pp.23-35. Oxford: Oxford University Press.

McDowell, J. 2018b. Perceptual Experience and Empirical Rationality. Analytic Philosophy 59(1): 89-98.

McDowell, J. 2019. Responses to Brewer, Gupta, and Siegel. Philosophical Issues 29(1): 390402.

Peacocke, C. 1992. A Study of Concepts. Cambridge: MIT Press.

Schellenberg, S. 2013. A Trilemma About Mental Content. In: J. K. Schear (ed.) Mind, Reason, and Being in the World: The McDowell-Dreyfus Debate, pp.272-282. London; New York: Routledge.

Schulting, D. 2016. Kantian Non-conceptualism. London: Palgrave Macmillan. 
Siegel, S. 2010. The Contents of Visual Experience. New York: Oxford University Press. Smith, D.; McIntyre, R. 1982. Husserl and Intentionality. Dordrecht: Reidel.

Thomson, I. 2001. Heidegger, Art, and Postmodernity. Cambridge: Cambridge University Press.

Travis, C. 2004. The Silence of the Senses. Mind 113(449): 57-94.

Travis, C. Reason's Reach. 2007. European Journal of Philosophy 15(2): 225-248.

Travis, C. 2013. Unlocking the Outer World. In: Perception - Essays after Frege, pp.223-258. Oxford: Oxford University Press.

Travis, C. 2018. The Move, The Divide, The Myth and its Dogma. In: J. Gersel; R. Thybo Jensen; M. Thaning Sørensen \& S. Overgaard (ed.), In the Light of Experience - Essays on Reasons and Perception, pp.36-76. Oxford: Oxford University Press.

Tye, M. 2007. Intentionalism and the Argument from No Common Content. Philosophical Perspectives 21(1): 589-613.

Wilson, K. 2018. Are the Senses Silent? In: T. Dobler \& J. Collins (ed.), Charles Travis on Language, Thought, and Perception, pp.199-221. Oxford: Oxford University Press.

Wrathall, M. 2011. Heidegger and Unconcealment. Cambridge: Cambridge University Press.

\section{Notas}

${ }^{1}$ McDowell, mais recentemente, tem tomado a noção de "conteúdo" como "uma implicação da ideia de que capacidades conceituais estão em operação na experiência" (McDowell 2019, p.394) e não mais como uma ideia de que a experiência perceptual possui conteúdo representacional (cf. McDowell (2005) e Brewer (2019)). Como veremos, Travis, no debate em questão, denomina aqueles que defendem algum tipo de noção de conteúdo com o termo "representacionista". Na medida em que Travis - assim como outros autores (ver, por exemplo, Gersel (2018) e Wilson (2018)) - entendem McDowell como sendo, nesse mesmo sentido específico, um representacionista, iremos também optar por considerar McDowell como sendo um representacionista. Nessa mesma perspectiva, tomaremos a nossa posição no debate, assim como a de Heidegger, como sendo representacionista, na medida em que defenderemos que a experiência perceptual possui conteúdo, no sentido específico discutido no presente artigo.

${ }^{2}$ Os termos "experiência" e "percepção", no debate em questão, dizem respeito a episódios sensórios como visão, tato, olfato, audição etc., que podem ocorrer em um indivíduo. Nesse sentido, ao falarmos de "experiências" não estaremos nos referindo, de modo mais abrangente, a outros tipos de experiências como pensamentos, emoções, imaginações e assim por diante. No mais, é importante ressaltar que, no presente artigo, os termos "experiência perceptual", "experiência" e "percepção" invariavelmente aparecerão como intercambiáveis.

${ }^{3}$ Nas citações da Crítica da Razão Pura, usaremos o sistema de referência com a abreviação "CRP", acrescida das edições "A" ou "B" e seus respectivos parágrafos. Ainda sobre Kant, é importante notar que a leitura conceitualista defendida por McDowell não é ponto pacífico. Para uma discussão abrangente, assim como para leituras não conceitualistas da filosofia kantiana, ver Schulting (2016).

${ }^{4}$ No debate em questão, é importante esclarecer que "conceitos" não devem ser entendidos no contexto de uma abordagem ontológica, que busque avançar uma teoria sobre aquilo que um conceito é. No caso, a ideia de "conceitual" se apresenta antes no contexto de uma 
defesa ou não (não conceitualismo) de uma imagem filosófica da experiência humana que entende nossas capacidades conceituais e racionais como estando presentes em nossa percepção do mundo, capacidades estas que, segundo os chamados "conceitualistas", seriam imprescindíveis para guiar nossas crenças, juízos, ações e assim por diante.

${ }^{5}$ Outros defensores da ideia de que a experiência perceptual possui conteúdo nesses mesmos termos são Byrne (2001) e Tye (2007).

${ }^{6}$ Para visões semelhantes, ver Brewer (2011), Campbell (2002), Fish (2009) e Martin (2004).

${ }^{7}$ Citação traduzida a partir da tradução em inglês que Travis faz da respectiva passagem presente em Frege (1984) [1918-1919].

${ }^{8}$ Todas as traduções de citações em inglês presentes neste artigo foram feitas por mim, e, portanto, são de minha responsabilidade.

${ }^{9}$ Em geral, na literatura filosófica sobre a percepção a visão é tomada como sendo o sentido paradigmático. Entendemos, sem dúvida, que uma abordagem mais abrangente sobre os sentidos, que dê conta também do tato, olfato, audição etc., é bem vinda ao debate. Contudo, no presente artigo vamos nos ater principalmente à visão, sentido este que é o tema central para McDowell e Travis.

${ }^{10}$ Outros oponentes de Travis são, por exemplo, Siegel (2010), Schellenberg (2011)

${ }^{11}$ Ver Wilson (2018) para uma detalhada e excelente exposição do que está em jogo para Travis no debate aqui discutido.

12 A noção de condição de correção, com efeito, é frequentemente utilizada como argumento positivo em favor da ideia de que a experiência perceptual possui conteúdo representacional. Segundo Tye (2006, p.504), por exemplo, "[se a] experiência visual (...) possui condições de correção: é correta ou precisa em certas circunstâncias; incorreta ou imprecisa em outras (...) [então] experiências visuais (...), assim como crenças, são representações de como as coisas são [e logo] as experiências visuais (...) possuem conteúdo representacional".

${ }^{13}$ Contudo, é importante notar que Travis se opõe também a posições não conceitualistas, como, por exemplo, a de Peacocke (1992), o que indica que o interlocutor de McDowell não rejeita apenas teses representacionistas de tipo conceitualista.

${ }^{14}$ A ilusão de Müller-Lyer é um célebre exemplo. Esta ilusão nos apresenta dois segmentos A e B com comprimentos idênticos, mas que dão a impressão de possuírem dimensões distintas. Em uma ilusão desse tipo, aquilo que é dado na percepção é revogável (defeasible), na medida em que podem haver circunstâncias onde um sujeito tem razões para acreditar que sua experiência é enganosa, podendo, assim, ajuizar que as coisas representadas em sua experiência não são do modo como aparecem. Se, do contrário, o sujeito não possui consciência dessas razões, ele tende a ajuizar que as coisas são do modo como aparecem.

${ }^{15}$ Ver Travis (2007).

${ }^{16}$ Ver McDowell (2009, p.261).

${ }^{17}$ Ver Travis (2018).

${ }^{18}$ João Vergilio Gallerani Cuter traduz thinkables por “aquilo que é pensável”. Apesar de sua tradução capturar adequadamente o que está em jogo para o uso que McDowell faz do termo, iremos optar, em nosso texto, por manter a expressão em inglês, no intuito de não darmos margem para ambiguidades ao sentido do termo "conteúdo".

${ }^{19}$ Ver Travis (2018, p.42).

${ }^{20}$ Mesmo autores que não discutem Heidegger no contexto de uma leitura analítica, como, 
por exemplo, Casanova (2010) e Thomson (2001) também parecem sugerir uma leitura não conceitualista do autor alemão, ainda que a mesma se dê em outros termos. Já para outra leitura conceitualista, ver Dennis (2012).

${ }^{21}$ A noção de "contexto", a partir da terminologia heideggeriana, é definida por Golob (2014, p.83) do seguinte modo: "A forma explicativamente básica da intencionalidade do Dasein consiste na capacidade de localizar uma entidade ou entidades, a variável a, dentro de um contexto relevante, relacional, a variável b. A forma explicativamente primária que a variável b assume é a rede de relações que Heidegger chama de 'mundo"'.

${ }^{22}$ Tais especificidades, que remontam a leitura que Heidegger faz da noção husserliana de noema, não poderão, por questão de espaço, ser discutidas no detalhe aqui. Mas a título de uma breve contextualização, vejamos, em termos bastante gerais, o pano de fundo da questão. Segundo Golob (2014), Heidegger vai contra uma leitura que identifica o noema husserliano com um sentido fregeano, ou seja, com uma entidade abstrata que se distingue tanto do ato de pensar quanto do objeto. Tal leitura do texto de Husserl seria aquela defendida pela chamada "interpretação da Costa Oeste", personificada em nomes como Føllesdal (1969) e Smith \& McIntyre (1982). Em contrapartida, a variável "a" da estrutura "a como b" deveria ser entendida como sendo a entidade ela mesma, nos moldes de uma interpretação russerliana. Entre outras razões, é também nesse sentido que a posição de Heidegger poderia ser identificada com uma espécie de "representacionismo mínimo", na medida em que a variável "a", no interior da explicação da estrutura-"como", não seria uma entidade bruta, já que a experiência desta entidade, em termos heideggerianos, possuiria condições de correção. Desse modo, Golob sugere que Heidegger estaria mais alinhado com a chamada "interpretação da Costa Leste" (ver Drummond (1990)), que entende, por sua vez, que a distinção entre noema e objeto é metodológica, e não ontológica. Segundo tal leitura, o noema não seria um intermediário entre sujeito e objeto, e sim o objeto ele mesmo considerado fenomenologicamente, ou seja, em termos de seu significado. Ver Golob (2014, p.91-6).

${ }^{23}$ Cf. Golob (2014, p.100).

\section{Agradecimentos}

A realização deste trabalho teve o apoio da Coordenação de Aperfeiçoamento de Pessoal de Nível Superior (CAPES). Agradeço os valiosos comentários feitos por André Abath à primeira versão do texto. Sou grato também aos pareceristas — pela leitura atenta e pelas sugestões de melhorias ao texto - bem como à equipe editorial da Principia: an International Journal of Epistemology. Agradeço ainda as conversas com Sacha Golob e Stephen Houlgate sobre a filosofia de Heidegger e os temas "continentais" aqui abordados. 